\title{
WALDEMAR FISCHER'S MODIFICATION OF VOLHARD'S METHOD FOR THE VOLUMETRIC ESTIMATION OF MANGANESE, AND ITS COMPARISON WITH OTHER WELL-KNOWN METHODS.*
}

\author{
By EDWARD CAHEN, A.R.C.Sc., F.I.C., AND HARRY F. V. LITTLE, \\ A.R.C.Sc., B.Sc. \\ (Read at the Meeting, December 7, 1910.)
}

\begin{abstract}
AN examination has been made of the modification recommended by $W$. Fischer (Zeitsch. Anal. Chem., 1909, 48, 751; Analyst, 1910, 35, 80) of Volhard's wellknown method for the determination of manganese, with the object of determining its degree of accuracy and of applying it to the estimation of manganese in highgrade ores and alloys. A detailed account of the results is recorded below, from which it will be seen that the process compares very favourably with several other well-established methods.
\end{abstract}

\section{Examination of Fischer's Modification of Volhard's Method.}

Volhard's method (Annalen, 1879, 198, 318) for the estimation of manganese consists in titrating a hot solution of manganous sulphate containing zinc sulphate with potassium permanganate, when manganese dioxide is precipitated, a reaction occurring which is essentially represented by the equation

$$
3 \mathrm{MnSO}_{4}+2 \mathrm{KMnO}_{4}+2 \mathrm{H}_{2} \mathrm{O}=5 \mathrm{MnO}_{2}+\mathrm{K}_{2} \mathrm{SO}_{4}+2 \mathrm{H}_{2} \mathrm{SO}_{4}
$$

The end of the titration is recognised by the supernatant liquid acquiring a faint permanent pink coloration.

Few analytical methods have been subjected to more criticism and modification than that just outlined, and the numerous though frequently conflicting statements concerning it that have appeared from time to time at least indicate that the method is one that appeals to the practical chemist. It has been generally recognised that the method gives low results, which is not surprising when the extreme difficulty of precipitating manganese exclusively in the form of dioxide is remembered ( $c f$. Wright

* This work was carried out according to the terms of the Analytical Chemistry Investigation Scheme, and part of the cost was covered by a grant from the Researeh Fund. 
and Menke, J. Chem. Soc., 1880, 37, 22 ; Gorgeu, Bull. Soc. Chim., 1893, 11 [iii.], 490 ; Gooch and Austin, Amer. J. Sci., 1898, 5, 260). The presence of chloride is generally held to lower the results still further. An often-used modification of Volhard's procedure consists in titrating in the presence of suspended zinc oxide or calcium carbonate, which neutralises the acid formed during the titration. The temperature of titration also influences the results. It will therefore be apparent that accurate results cannot be expected from any of the usual modifications of Volhard's method unless the working value of the permanganate solution is empirically fixed by titration against a known amount of pure manganese salt.

The procedure recommended by Fischer (loc. cit.) claims to yield accurate results even in the presence of chloride in high concentration, while the permanganate may be standardised with sodium oxalate; it is said that the precipitated manganese dioxide contains the theoretical amount of available oxygen. The following account of the method is quoted from the ANaLYst (loc. cit:) :

"The solution of manganese in hydrochloric or sulphuric acid is diluted to 500 c.c., neutralised with caustic soda until a slight precipitate persists on shaking, and the precipitate just redissolved by cautious addition of dilute sulphuric acid. One grm. of freshly ignited zinc oxide and 10 grms. of zinc sulphate are next added, the solution heated to boiling, and titrated hot with permanganate. When the colour of the permanganate is no longer discharged, 1 c.c. of glacial acetic acid is added. The colour usually disappears, and the precipitate settles instantly. Permanganate is then added drop by drop until the solution becomes permanently pink, when the total consumption of permanganate accurately measures the manganese present."

To the above description it should be added that Fischer directs that the titration should be performed with frequent boiling and shaking, and that in the absence of chloride the quantity of zinc sulphate should be increased (about 10 grms. for each 10 c.c. $\frac{\mathrm{N}}{10} \mathrm{KMnO}_{4}$ required).

From the equation given above it will be seen that 1 c.c. of $\frac{\mathrm{N}}{\mathbf{1} 0} *$ permanganate only corresponds to $0.001648 \mathrm{grm}$. of manganese present as manganous salt; and, consequently, an error of 0.2 c.c. only corresponds to $0.00033 \mathrm{grm}$. of manganese. Nevertheless, this means an error of 0.6 per cent. in a titration requiring 33 c.c. The relatively large percentage error corresponding to an actual error of a fraction of a milligram of manganese does not appear to have been properly appreciated by several other workers (cf. von Longi and Camilla, Gazz., 1897, 27, 97), who have reported favourably of procedures which lead to actual errors of several times the magnitude mentioned above.

Materials Employed-(a) Potassium Permanganate.-The purest commercial salt was twice recrystallised from water at $65^{\circ}$ to $70^{\circ} \mathrm{C}$, and the product dried over sulphuric acid.

(b) (c) (d) Manganous Sulphate, Sodium Chloride, Zinc Sulphate.-The purest commercial preparations were used. Filtered solutions of the two latter salts of known concentration were measured out as required.

* By decinormal permanganate is here meant the usual solution, containing 3.16 grms. of the salt per litre, which is decinormal in acid solution. 
(e) Zinc Oxide.-Pure precipitated zinc oxide was calcined in a muffle furnace. It was tested for impurity by de Koninck's method (J. Soc. Chem. Ind., 1905, 24, 152), with negative results.

(f) Glacial Acetic Acid. - Kahlbaum's purest preparation was usually employed, but the best commercial acid was found to contain nothing oxidisable by permanganate.

The majority of the test analyses were carried out by the following method, which was used in a series of experiments by Fischer: An approximately $\frac{N}{10}$ permanganate solution was prepared, and portions of 50 c.c. accurately measured out and evaporated to dryness with concentrated hydrochloric acid. The resulting manganous chloride was dissolved in water, rinsed into a litre flask, the requisite amounts of sodium chloride and zinc sulphate added, and the solution titrated by Fischer's process with the remaining permanganate solution. The theoretical volume of the latter required is 33.33 c.c., as will be seen at once from the equation, and three times the actual titration error in c.c. gives the percentage error.

It was originally intended to observe accurately the end-point obtained before the introduction of the acetic acid, and then to finish the titration in acetic acid solution; but it was soon found that this would consume considerable time without yielding results of any practical value. The accurate observation of the first endpoint was therefore given up; the titration was carriea out in the presence of zinc oxide until within about 1 c.c. of the theoretical value, when the acetic acid was added and the titration accurately finished.

As the result of a large number of test experiments, which frequently led to most curiously inconsistent results, it was eventually concluded that the titration cannot be completed in boiling solution, as directed by Fischer, since under these circumstances it is not possible to rely upon obtaining a definite end-point. Subsequently, it was discovered that this point had been insisted upon by von Longi and Camilla (loc. cit.) in their interesting review of Volhard's method. The disappearance of the permanganate end-point in boiling solution is probably accelerated by contact with the manganese precipitate, in view of the well-known instability of permanganate in the presence of the solid dioxide (Morse, Hopkins and Walker, Amer. Chem. J., 1896, 18, 401).

The following method, differing very slightly in detail from Fischer's, can be relied upon to afford satisfactory results:

The neutral solution of manganese salt, containing 10 grms. of zinc sulphate, is diluted to 500 c.c. and heated to boiling. One grm. of freshly ignited zinc oxide is then added, and the solution titrated with permanganate, with frequent heating to boiling, and shaking, until the permanganate is no longer decolourised. The solution is then cooled under the tap for a minute or two, 1 to 2 c.c. of glacial acetic acid are added, and the liquid thoroughly shaken. The hot but not boiling liquid is then titrated further with permanganate, added a few drops at a time, with vigorous shaking for half a minute after each addition, until the supernatant liquid retains its pink colour after being well shaken several times. The end-point is then reached, and the pink coloration will persist, as a rule, for one or two hours.

In this form, Fischer's process leaves little to be desired as far as accuracy is 
VOLHARD'S ME'THOD FOR THE ESTIMATION OF MANGANESE, ETC. 55

concerned, while the remarkable manner in which the precipitate subsides after the addition of acetic acid enables the titrations to be finished with the greatest ease.

The results obtained are summarised in Tables I. to IV. Those given in Tables I., II., and IV., represent mean values, each experiment having been repeated several times, with concordant results. The weights of zinc sulphate specified refer to anhydrous salt; it is not clear from Fischer's paper whether he means anhydrous salt or heptahydrate. The results have not been corrected by "blank experiments," which fact may partly account for the rather high results obtained in the presence of large amounts of sodium chloride and zinc sulphate.

Table I. shows that accurate results are obtained when chloride is present to the extent of 10 grms. of sodium chloride; further, that there is little necessity to increase the quantity of zinc sulphate beyond 5 grms. The comparative results of Table II. show that an increase in the amount of chloride present from 10 to 40 grms. of sodium chloride has no influence on the accuracy of the results. Also, that in the total absence of chloride the quantity of permanganate required for titration increases slightly with an increase in the quantity of zinc sulphate present, the results being rather low when littie zinc sulphate is added. The quantity of this salt recommended by Fischer (loc. cit., p. 53) seems, however, unnecessarily large, and it is preferable to operate in chloride solution rather than increase the amount of zinc sulphate present beyond $10 \mathrm{grms}$.

\section{TABLE I.}

These values were obtained from manganous chloride, prepared, as described on p. 53 , from 50 c.c. of the same $\frac{\mathrm{N}}{10}$ permanganate used for the titration.

$\mathrm{KMnO}_{1}$ (theory for titration) $=33.33 \mathrm{c.cm}$.

\begin{tabular}{|c|c|c|c|c|c|c|c|c|c|c|}
\hline $\begin{array}{c}\mathrm{ZnSO}_{4} . \\
\text { Grms. }\end{array}$ & & $\begin{array}{l}\text { NaCl. } \\
\text { Grms. }\end{array}$ & & $\underset{\text { C.C. }}{\mathrm{KMnO}_{4} .}$ & & $\begin{array}{l}\mathrm{ZnSO}_{4} . \\
\text { Grms. }\end{array}$ & & $\begin{array}{l}\text { NaCl. } \\
\text { Grms. }\end{array}$ & & $\begin{array}{c}\mathrm{KMnO}_{4} . \\
\text { C.C. }\end{array}$ \\
\hline 5 & $\ldots$ & 0 & .. & $33 \cdot 40$ & $\cdots$ & 5 & .. & 5 & $\ldots$ & $33 \cdot 30$ \\
\hline 10 & $\ldots$ & 0 & $\ldots$ & $33 \cdot 40$ & $\ldots$ & 10 & $\ldots$ & 5 & $\ldots$ & $33 \cdot 45$ \\
\hline 20 & $\ldots$ & 0 & $\ldots$ & $33 \cdot 50$ & $\ldots$ & 20 & $\ldots$ & 5 & $\ldots$ & $33 \cdot 40$ \\
\hline 5 & $\ldots$ & 2 & $\ldots$ & $33 \cdot 30$ & $\ldots$ & 5 & $\ldots$ & 10 & $\ldots$ & $33 \cdot 35$ \\
\hline 10 & $\ldots$ & 2 & $\ldots$ & $33 \cdot 40$ & $\ldots$ & 10 & $\ldots$ & 10 & $\ldots$ & $33 \cdot 45$ \\
\hline 20 & $\ldots$ & 2 & $\ldots$ & $33 \cdot 40$ & $\ldots$ & 20 & $\ldots$ & 10 & $\ldots$ & $33 \cdot 45$ \\
\hline
\end{tabular}

TABLE II.

$\mathrm{MnSO}_{4}$ soln. $=6$ grms. per litre.

25 c.c. used in each experiment.

\begin{tabular}{|c|c|c|c|c|c|c|c|c|c|c|}
\hline $\begin{array}{c}\mathrm{ZnSO}_{4} . \\
\text { Grms. }\end{array}$ & & $\begin{array}{l}\mathrm{NaCl} \text {. } \\
\text { Grms. }\end{array}$ & & $\begin{array}{c}\mathrm{KMnO} \\
\text { C.C. }\end{array}$ & & $\begin{array}{l}\mathrm{ZnSO}_{4} \\
\text { Grms. }\end{array}$ & & $\begin{array}{l}\mathrm{NaCl} \text {. } \\
\text { Grms. }\end{array}$ & & $\underset{\text { C.C. }}{\mathrm{KMnO}_{4}}$ \\
\hline 10 & $\ldots$ & 5 & $\ldots$ & $30 \cdot 55$ & $\ldots$ & 5 & $\ldots$ & 40 & . & $30 \cdot 65$ \\
\hline 5 & $\ldots$ & 10 & $\ldots$ & $30 \cdot 55$ & $\ldots$ & 10 & $\ldots$ & 40 & .. & $30 \cdot 60$ \\
\hline 10 & $\ldots$ & 10 & $\ldots$ & $30 \cdot 60$ & $\ldots$ & 5 & $\ldots$ & 0 & .. & $30 \cdot 40$ \\
\hline 5 & $\ldots$ & 20 & $\ldots$ & 30.55 & $\ldots$ & 10 & $\ldots$ & 0 & $\ldots$ & $30 \cdot 50$ \\
\hline 10 & $\ldots$ & 20 & $\ldots$ & $30 \cdot 50$ & $\ldots$ & 15 & $\ldots$ & 0 & $\ldots$ & 30.50 \\
\hline 5 & $\ldots$ & 30 & $\ldots$ & 30.55 & $\ldots$ & 20 & $\ldots$ & 0 & $\ldots$ & 30.55 \\
\hline 10 & $\ldots$ & 30 & $\ldots$ & $30 \cdot 60$ & $\ldots$ & 30 & $\ldots$ & 0 & . & $30 \cdot 70$ \\
\hline
\end{tabular}


Table III. shows that, by increasing the concentration of the permanganate employed, it is possible to titrate accurately twice the quantity of manganese that can usually be conveniently taken.

\section{TABLE III.}

$\frac{\mathrm{N}}{\overline{5}} \mathrm{KMnO}_{4}$ used. Amount reduced $=50 \cdot 11$ c.c. Theory for titration $=33 \cdot 41$ c.c.

$\begin{array}{rlclc}\begin{array}{c}\mathrm{ZnSO}_{4} . \\ \text { Grms. }\end{array} & \begin{array}{c}\text { NaCl. } \\ \text { Grms. }\end{array} & & \begin{array}{c}\mathrm{KMnO}_{4} . \\ \mathrm{C.C} .\end{array} \\ 10 & \ldots & 10 & \ldots & 33 \cdot 45 \\ 10 & \ldots & 20 & \ldots & 33 \cdot 50 \\ 10 & \ldots & 30 & \ldots & 33 \cdot 45 \\ 5 & \ldots & 0 & \ldots & 33 \cdot 30 \\ 10 & \ldots & 0 & \ldots & 33 \cdot 45 \\ 20 & \ldots & 0 & \ldots & 33 \cdot 40 \\ 30 & \ldots & 0 & \ldots & 33 \cdot 45\end{array}$

\section{TABLE IV.}

$50 \cdot 11$ c.c. $\mathrm{KMnO}_{4}$ soln. reduced and titrated.

25 c.c. $\mathrm{KMnO}_{4}$ (approx. $\frac{\mathrm{N}}{10}$ ) $=24 \cdot 66$ c.c. $\mathrm{Na}_{2} \mathrm{~S}_{2} \mathrm{O}_{3}$. Theory for $\mathrm{KMnO}_{4}=33 \cdot 41$ c.c.

\begin{tabular}{|c|c|c|c|c|c|c|c|}
\hline $\begin{array}{c}1 . \\
\mathrm{ZnSO}_{4} . \\
\text { Grms. }\end{array}$ & $\begin{array}{c}2 . \\
\text { NaCl. } \\
\text { Grms. }\end{array}$ & $\begin{array}{c}3 . \\
\mathrm{KMnO}_{4}, \\
\text { C.C. to } \\
\text { End-pt. }\end{array}$ & $\begin{array}{c}4 . \\
\mathrm{KMnO}_{4}, \\
\text { Total Vol. } \\
\text { added. }\end{array}$ & $\begin{array}{c}5 . \\
\mathrm{Na}_{2} \mathrm{~S}_{2} \mathrm{O}_{3}, \\
\text { C.C. for } \\
\text { Ppt. }\end{array}$ & $\begin{array}{c}6 . \\
\mathrm{KMnO}_{4} \text {, } \\
\text { Equiv. to } \\
5 .\end{array}$ & $\begin{array}{c}{ }^{7 .} \\
\mathrm{Na}_{2} \mathrm{~S}_{2} \mathrm{O}_{3}, \\
\text { C.C. for } \\
\text { Filtrate. }\end{array}$ & $\begin{array}{c}8 . \\
\mathrm{KMnO}_{4}, \\
\text { Equiv. to } \\
4-7 .\end{array}$ \\
\hline 10 & 0 & $33 \cdot 40$ & $34 \cdot 50$ & $33 \cdot 10$ & 33.55 & 1.05 & $33 \cdot 44$ \\
\hline 10 & 5 & 33.45 & $34 \cdot 50$ & 32.96 & 33.41 & 1.00 & $33 \cdot 49$ \\
\hline 10 & 10 & $33 \cdot 48$ & $34 \cdot 50$ & 33.05 & $33 \cdot 50$ & 0.98 & 33.51 \\
\hline 10 & 20 & $33 \cdot 45$ & $34 \cdot 50$ & $33 \cdot 04$ & $33 \cdot 49$ & $1 \cdot 00$ & 33.49 \\
\hline 10 & 30 & 33.55 & 34.50 & 33.05 & 33.50 & 0.85 & 33.64 \\
\hline 10 & 40 & $33 \cdot 55$ & $34 \cdot 50$ & 33.05 & $33 \cdot 50$ & 0.80 & 33.69 \\
\hline 10 & 50 & $33 \cdot 55$ & $34 \cdot 50$ & $33 \cdot 02$ & $33 \cdot 47$ & 0.89 & $33 \cdot 60$ \\
\hline
\end{tabular}

Table IV. summarises the results of experiments made to determine the oxidising power of the precipitate. After titrating in the manner previously described (p. 54), a slight excess of permanganate was added to the solution, and the whole shaken vigorously for several minutes. The solution was then cooled, the precipitate filtered off on asbestos, and its available oxygen determined by dissolving in dilute hydrochloric acid and potassium iodide (Pickering, J. Chem. Soc., 1880, 37, 128), and titrating the liberated iodine with sodium thiosulphate, itself standardised against the permanganate solution. The excess of permanganate in the filtrate was also determined iodimetrically. The results obtained by these two processes are seen to be in substantial agreement with those obtained by direct titration with permanganate.

In applying Fischer's process in actual practice, a difficulty arises unless the 
VOLHARD'S METHOD FOR THE ESTIMATION OF MANGANESE, ETC. 57

volume of permanganate required is known to within 3 or 4 c.c., since, owing to the slowness with which the finely divided precipitate settles in the presence of zinc oxide, the time required for a titration is unduly prolonged, and the first endpoint is difficult to observe. The simplest method of avoiding this is to conduct duplicate titrations, as recommended by Fischer. If the acetic acid is added in one case before the addition of any permanganate, a low result is obtained; but the titration is rapidly effected, and the result serves as a useful guide in the titration proper. An alternative procedure to obtain a preliminary result quickly consists in adding several grams of zinc oxide, omitting the zinc sulphate, and titrating in nearly boiling solution. The experiments recorded in Table IV. naturally suggest a backward titration method; the procedure necessary will be obvious from what has been already said.

\section{Comparison of Fischer's Method with Other Methods.}

The practical value of Fischer's method has been tested by applying it to the estimation of manganese in three specimens of ferromanganese.

The finely divided samples (1 grm.) were dissolved in 25 c.c. strong hydrochloric acid, the solutions oxidised with 10 c.c. nitric acid, and evaporated to a small bulk; 25 c.c. hydrochloric acid were again added, and the evaporation to a small bulk repeated. The solutions were diluted to 300 c.c. with cold water, and zinc oxide added little by little, with shaking, until the precipitate suddenly coagulated. The liquids were then diluted to 1 litre, filtered through dry papers from ferric hydroxide and zinc oxide, and aliquot parts (100 c.c.) of the filtrates measured out and titrated. The error caused by neglecting the volume of the precipitate is inappreciable. The permanganate solution was conveniently made to contain 3.5 grms. per litre, and was standardised against pure sodium oxalate (Sörensen), which is undoubtedly one of the most accurate methods that can be employed for this purpose.

It should be mentioned, in passing, that the commonly-employed zinc oxide method of separating iron from manganese does not always lead to satisfactory results, although it is not possible to assign the reason.

The method outlined above can be easily carried out in an hour and a half, and, of course, a number of analyses can be finished in proportionately less time.

For purposes of comparison, the samples have also been analysed for manganese by the following three well-known methods :

(a) Basic Acetate Separation and Subsequent Gravimetric Estimation of Manganese as $\mathrm{Mn}_{3} \mathrm{O}_{4}$.-The separation of the iron was effected twice with ammonium acetate in the usual manner. The manganese precipitate was crushed to powder after a preliminary ignition, and then ignited in the muffle to constant weight. This method appears to give much better results than the statements of some of its critics would lead one to expect ( $c f$. Saniter, J. Soc. Chem. Ind., 1894, 13, 113).

(b) Bismuthate Process. - This was carried out according to the procedure of Reddrop and Ramage (J. Chem. Soc., 1895, 67, 268), except that only half the amount of manganese was employed, and ferrous sulphate was substituted for hydrogen peroxide, as recommended by Brearley and Ibbotson (Chem. News, 1901, 
84, 247). For accuracy, rapidity, and simplicity, this method leaves nothing to be desired.

(c) Pattinson's Process. - This was carried out as described by Pattinson (J. Soc. Chem. Ind., 1891, 10, 337); bromine-water was the oxidising agent employed. It was preferred to standardise the bichromate solution employed upon the precipitate obtained from a known amount of manganese chloride (prepared by reducing a weighed quantity of pure permanganate) rather than with iron wire or ferrous ammonium sulphate; the latter procedure led to slightly higher results. It is necessary to point out, moreover, that commercial ferric chloride contains an appreciable quantity of manganese; consequently, if ferric chloride is added to the solution as Pattinson directs, the amount of manganese contained therein* should be allowed for, or an error of 0.4 to 0.5 per cent. manganese may be thereby introduced in dealing with an 80 per cent. ferromanganese. By standardising the dichromate on pure permanganate to which has been added an amount of ferric chloride equal to that used in an estimation, and arranging that the volume of standard solution required shall be approximately equal to that used in an actual analysis, the error due to this cause may be eliminated.

The results obtained are summarised in Table V. The agreement is very satisfactory; the data given are the mean values derived from several concordant analyses, and not "selected" from a number of results. It will be observed that the results obtained by Pattinson's method, employing ferrous ammonium sulphate as standard, are rather higher than those obtained by the comparative method or by other methods. It has not been found possible to duplicate the results obtained by Mr. J. E. Stead, $\dagger$ and which be forwarded after the results by the first three methods mentioned in Table V. had been obtained. It was at his suggestion that Pattinson's method was then tried, with the foregoing results. For very kindly supplying the samples of ferromanganese for analysis, and forwarding his own analytical results for the manganese, the authors wish to express their cordial thanks to Mr. Stead.

In confirmation of the substantial accuracy of the results set out in Table V., the following analytical results are appended (Table VI.). The results for iron are probably rather high, since the alloys were dissolved in hydrochloric acid and the iron determined gravimetrically; but they are sufficiently accurate for the purpose. For assistance in estimating the carbon, and for the loan of the necessary apparatus, the authors wish to acknowledge their indebtedness to Mr. A. E. Wraight.

Fischer's method has also been tried on two samples of pyrolusite; the results, with comparative data by two other methods, are set out in Table VII. It will be seen that here, again, the agreement between the volumetric methods is very satisfactory, while the gravimetric results are distinctly higher. This is in accordance with Saniter's remarks upon the gravimetric method as applied to ores (J. Soc.

* This is readily determined by boiling with ammonia and a little hydrogen peroxide, dissolving the washed precipitate in nitric acid and a little sulphurous acid, and estimating the manganese by the bismuthate method.

+ The results obtained by Mr. Stead were 82.02 per cent., 80.06 per cent., and 60.50 per cent., respectively. 
VOLHARD'S METHOD FOR THE ESTIMATION OF MANGANESE, ETC. 59

Chem. Ind., 1894, 13, 113); in the above analyses the manganese was precipitated with bromine and ammonia directly in the filtrate from the basic ferric acetate. The volumetric methods are therefore to be preferred to the gravimetric process, unless the latter is carried out in a more refined manner, taking the necessary precautions to prevent co-precipitation of other metals, and analysing the final precipitate for impurities; it then becomes too tedious for technical work.

TABLE V.

\begin{tabular}{|c|c|c|c|}
\hline \multirow{2}{*}{ Method of Analysis. } & \multicolumn{3}{|c|}{ Sample of Ferromanganese. } \\
\hline & No. 80. & No. 75 . & No. 63. \\
\hline \begin{tabular}{llll} 
Volhard-Fischer & $\ldots$ & $\ldots$ & $\ldots$ \\
Bismuthate & $\ldots$ & $\ldots$ & $\ldots$ \\
Gravimetric & $\ldots$ & $\ldots$ & $\ldots$ \\
Pattinson (comparative) & $\ldots$ & $\ldots$ \\
$\quad, \quad$ (standard ferrous am- \\
\multicolumn{4}{c}{ monium sulphate)... }
\end{tabular} & $\begin{array}{l}80 \cdot 95 \\
80 \cdot 92 \\
80 \cdot 98 \\
80 \cdot 93 \\
81 \cdot 21\end{array}$ & $\begin{array}{l}79 \cdot 15 \\
79 \cdot 15 \\
79 \cdot 01 \\
79 \cdot 12 \\
79 \cdot 41\end{array}$ & $\begin{array}{l}59 \cdot 47 \\
59 \cdot 61 \\
59 \cdot 77 \\
59 \cdot 44 \\
\\
59 \cdot 65\end{array}$ \\
\hline
\end{tabular}

TABLE VI.

\begin{tabular}{|c|c|c|c|c|c|c|}
\hline Ferro. & Iron. & Carbon. & Silicon. & Phosphorus. & \multicolumn{2}{|c|}{ Manganese. } \\
\hline $\begin{array}{ccc}\text { No } & 80 & \ldots \\
& 75 & \ldots \\
\Rightarrow & 63 & \ldots\end{array}$ & $\begin{array}{l}11 \cdot 92 \\
13 \cdot 48 \\
33 \cdot 52\end{array}$ & $\begin{array}{l}6 \cdot 75 \\
6 \cdot 73 \\
6 \cdot 03\end{array}$ & $\begin{array}{l}0.50 \\
0.56 \\
0.64\end{array}$ & $\begin{array}{l}0.15 \\
0.21 \\
0.05\end{array}$ & $\begin{array}{c}\text { By Difference. } \\
80 \cdot 68 \\
79 \cdot 02 \\
59 \cdot 76\end{array}$ & \begin{tabular}{|c} 
From Table V. \\
80.95 \\
79.11 \\
59.57
\end{tabular} \\
\hline
\end{tabular}

TABLE VII.

\begin{tabular}{|c|c|c|c|c|}
\hline \multirow{2}{*}{$\begin{array}{l}\text { Sample of } \\
\text { Pyrolusite. }\end{array}$} & \multicolumn{4}{|c|}{ Method of Analysis. } \\
\hline & Volhard-Fischer. & Bismuthate. & & setric. \\
\hline $\begin{array}{l}\text { W. } \\
\text { E. }\end{array}$ & $\begin{array}{l}48 \cdot 75 \\
50 \cdot 35\end{array}$ & $\begin{array}{l}48 \cdot 72 \\
50 \cdot 50\end{array}$ & $\begin{array}{c}\text { Authors. } \\
49 \cdot 48 \\
51 \cdot 33\end{array}$ & $\begin{array}{c}\text { Riley and Harbord. } \\
\begin{array}{c}49 \cdot 63 \\
51 \cdot 34\end{array}\end{array}$ \\
\hline
\end{tabular}

The authors' grateful acknowledgments to Mr. J. E. Stead and Mr. E. A. Wraight have been already expressed; it remains, in conclusion, for them to express their thanks to Miss Helen Cunningham for kindly translating von Longi and Camilla's paper, to Messrs. Riley and Harbord for supplying the pyrolusites, together with their own analytical results for the same, and, finally, to Mr. A. Chaston Chapman for the generous help he has afforded them throughout the course of the work. 